\title{
Tratamiento primario (reducción de coloides-clarificación) de aguas residuales-efluente río Huatanay mediante operaciones unitarias de coagulación-Floculación y estabilización de $\mathrm{pH}$
}

\section{Primary treatment (reduction of colloids-clarification) of domestic wastewater-effluent river Huatanay through unit operations of coagulation-flocculation and stabilization oF $\mathrm{pH}$}

\author{
Verónika Isela Vera Marmanillo ${ }^{1,-[}$ \\ 1 Escuela Profesional de Ingeniería Ambiental, Universidad Andina del Cusco, Cusco, Perú.
}

\section{Resumen}

El trabajo de investigación pretendió demostrar la eficacia de los tratamientos primarios de aguas residuales domésticas, por medio de operaciones unitarias de coagulación-floculación y estabilización de $\mathrm{pH}$, con la finalidad de demostrar la sedimentabilidad óptima de coloides, macro y microsólidos y la clarificación del efluente por medio de procedimientos físico químicos. Se utilizó Al2 (SO4)3 como coagulante y polímeros aniónicos de Arifloc 301 como floculante. Se realizó pruebas con el fin de determinar la concentración efectiva de floculante en 5 unidades experimentales a micro escala, evidenciando que las sales de Aluminio reaccionan con la alcalinidad del agua y producen hidróxidos insolubles, favoreciendo a la formación del precipitado, estableciendo un puente químico donde las partículas de los coagulantes añadidos a la de los polímeros del floculante puedan absorber los coloides y microsólidos coadyuvando a la sedimentabilidad. Se determinó la dosis óptima, dosis eficiente y dosis excesiva de polímero, a través de una prueba de jarras en 5 unidades experimentales, se evaluó el lodo químico obtenido, por medio de gravimetría y determinación de características del mismo en cada una de las pruebas, en una relación óptima de 2:8. Fue necesario determinar parámetros de instalación de 5 efluentes experimentales, siendo la concentración eficiente la de 10:10 para la obtención de 300g de lodo químico sedimentado, logrando una reducción eficiente de coloides y clarificación óptima del efluente tratado.

Palabras clave: Coagulación, Floculación, Coloides, Lodo químico, Clarificación

\begin{abstract}
The research work aims to demonstrate the effectiveness of the primary treatments of domestic wastewater, by means of unitary operations of coagulation-flocculation and $\mathrm{pH}$ stabilization, in order to demonstrate the optimal sedimentation of colloids, macro and microsolids and the clarification of the effluent by means of physical-chemical procedures. A12 (SO4)3 was used as coagulant and anionic polymers of Arifloc 301 as a flocculant. For this, tests were carried out in order to determine the effective concentration of flocculant in 5 experimental units at micro scale, showing that aluminum salts react with the alkalinity of the water and produce insoluble hydroxides, favoring the formation of the precipitate, establishing a bridge chemical where the particles of the coagulants added to that of the flocculant polymers can absorb the colloids and microsolids contributing to sedimentation. The optimal dose, efficient dose and excessive dose of polymer was determined, through a test of jars in 5 experimental units, the chemical sludge obtained was evaluated, by means of gravimetry and determination of characteristics of the same in each of the tests, in an optimal ratio of 2 : 8 . For this, it was necessary to determine parameters of installation of 5 experimental effluents, with an efficient concentration of $10: 10$ to obtain $300 \mathrm{~g}$ of sedimented chemical sludge, achieving an efficient reduction of colloids and optimal clarification of the treated effluent..
\end{abstract}

Keywords: Coagulation, Flocculation, Colloids, Chemical sludge, Clarification

Citar como: Marmanillo, VIV. (2019). Tratamiento primario (reducción de coloides-clarificación) de aguas residuales-efluente río Huatanay mediante operaciones unitarias de coagulación-Floculación y estabilización de ph Rev Yachay, 8(1), 574-584.

Recibido: 08-07-2019; Aceptado 15-09-2019; Publicado: 12-12-2019

\section{Introducción}

Uno de los problemas más álgidos por los que atraviesa nuestro país es el mal manejo que se le da a los efluentes residuales domésticos e industriales, el $70 \%$ de las aguas residuales en el Perú no se descontaminan antes de su vertimiento o reúso, lo que ocasiona, no sólo la contaminación de la flora y fauna, sino enfermedades que conllevan a un problema de salud pública. Aunque existen entes reguladores, el 
principal problema en el Perú es la falta de conocimiento sobre la problemática ambiental que genera el agua residual no tratada. Es en ese sentido que, a través de nuestra investigación, damos un alcance, viable, económico, eficiente y accesible, para acceder de manera óptima a la primera etapa de un tratamiento de aguas residuales, minimizando y/o mitigando los impactos generados en el ambiente, problema que generan básicamente la presencia de coloides y microsólidos difíciles de tratar en un efluente crudo.

Actualmente, en la ciudad del Cusco las aguas residuales generadas por más de 400000 cusqueños, son tratadas en una PTAR; estas provenientes de distintas actividades, colegios, universidades, hospitales, industrias, etc. Se ha logrado minimizar el factor contaminante presente en estos efluentes a través de diversos tratamientos físicoquímicos y biológicos, cumpliendo con los parámetros que establece la normativa ambiental peruana. La simulación nos permitió saber la cantidad y los elementos que se usan para la correcta clarificación del efluente, siguiendo los procesos que se realizan en la PTAR y cuál es la importancia de un tratamiento primario. Para tal fin se aplicó un modelo dinámico y descriptivo que ameritaba un estudio previo sobre la composición y caracterización del efluente a tratar, así como la determinación de los parámetros $\mathrm{NO}_{3}, \mathrm{DQO}, \mathrm{TDS}, \mathrm{OD}, \mathrm{pH}, \mathrm{EC}, \mathrm{T}^{\circ}$ y Turbidez, realizados en gabinete.

Para tal fin se establecieron como objetivos:

i. Evaluar la efectividad de los procesos de reducción de coloides y clarificación, a través de operaciones unitarias en tratamiento primario de aguas residuales, como coagulación-floculación y estabilización de pH para las muestras de efluente del Río Huatanay.

ii. Detallar los parámetros físicos y químicos como: $\mathrm{pH}$, color, turbiedad, temperatura, nitratos, DQO, OD, EC, TDS

iii. Determinar la concentración de floculante-coagulante necesaria para tratamiento primario de la muestra-efluente.

iv. Especificar cuántos gramos de lodo químico por cada litro de agua residual se generó en cada una de las muestras.

v. Identificar la muestra más eficiente para cumplir con los parámetros requeridos y obtener el agua más clarificada.

\section{Materiales y método}

El presente proyecto tiene un enfoque cuantitativo y diseño descriptivo. Se utilizaron 5 muestras representativas de $1 \mathrm{~L}$ cada muestra. El punto georeferenciado de toma de muestras fue $13^{\circ} 32^{\prime} 17^{\prime}$ 'S $-71^{\circ} 54$ ' $18^{\prime}$ 'O.

\section{Materiales}

- Recipiente con capacidad de $1 \mathrm{Lt}$

- Arifloc 301 polímero sintético - Floculante

- $\mathrm{Al}_{2}\left(\mathrm{SO}_{4}\right)_{3}$ - Coagulante

- 5 Muestras del Río Huatanay (1 litro cada muestra)

- $\quad$ Equipos de medición de parámetros $\mathrm{pH} \mathrm{T}^{\circ}$ TDS EC OD (Multiparámetro Graigar)

- Vasos de precipitado

- Equipo de burbujeo (para aireación)

- Turbidímetro

- Balanza analítica

- Frasco de plástico boca ancha

- Reactivos para DQO y $\mathrm{NO}_{3}$

- $\mathrm{NaOH}$ al $1 \% \mathrm{M}$

\section{Procedimiento}

\section{Toma de muestras}

1. Se tomaron cinco (5) muestras del Río Huatanay en el punto georeferenciado de $13^{\circ} 32^{\prime} 17^{\prime \prime} \mathrm{S}-71^{\circ} 54^{\prime} 18^{\prime}$ 'O, en frascos de polietileno de alta densidad HDPE de $1 \mathrm{~L}$ de capacidad.

2. En gabinete, se puso el efluente en un recipiente colector con tapa hermética para que se puedan realizar los procedimientos.

3. Se determinaron los parámetros de: $\mathrm{pH}, \mathrm{NO}_{3}, \mathrm{~T}^{\circ}$, turbidez, $\mathrm{CE}, \mathrm{OD}, \mathrm{DQO}$ y TDS, con los equipos de medición para cada parámetro. 
Adición de coagulante

1. Se añadió 30 gr de $\mathrm{Al}_{2}\left(\mathrm{SO}_{4}\right)_{3}$ Sulfato de Aluminio (volumen estándar estimado en pruebas de efectividad) como coagulante a cada muestra del efluente, se añadió mediante un equipo de burbujeo durante 3 minutos. Se dejó actuar por 3 días.

2. Se realizó la toma de los parámetros de $\mathrm{T}^{\circ}$ y $\mathrm{pH}$ de cada muestra.

Adición de floculante

1. Para esta etapa se realizó prueba de jarras para el Arifloc 301 que es un polímero sintético de manera sólida, para lo cual se agregó el floculante de $5 \mathrm{~g}, 7.5 \mathrm{~g}, 10 \mathrm{~g}, 12.5 \mathrm{~g}$ y $15 \mathrm{~g}$, respectivamente en cada muestra.

2. A cada muestra se le añadió la cantidad respectiva de floculante mediante burbujeo por un tiempo de 3 minutos. Se dejó actuar por 3 días.

\section{Extracción de lodo}

1. Una vez que se añadió el coagulante y el floculante, se observó el lodo sedimentado que se formó, y se procedió a extraer el efluente tratado hacia un recipiente colector.

2. El lodo químico que resultó de la adición del floculante y el coagulante, fue determinado gravimétricamente.

3. Se calculó la dosis de eficiencia, para lo cual se tomó la siguiente medida:

En un $1 \mathrm{~L}$ de efluente se usó $10 \mathrm{~g}$ de sulfato de aluminio $\mathrm{Al}_{2}\left(\mathrm{SO}_{4}\right)_{3}$ (volumen estándar estimado en pruebas de efectividad) y la proporción del $10 \mathrm{~g}$ del polímero sintético según la muestra determinada, a partir de ello se genera el lodo químico, para lo cual se realiza la suma de la cantidad de lodos generados más la cantidad de polímero sintético usado, mediante la siguiente ecuación:

$$
\text { Lodo final + Cantidad de Arifloc usado = Lodo total ... (1) Estabilización del ph }
$$

4. Se estabilizo el $\mathrm{pH}$ con $20 \mathrm{ml}$ de hidróxido de sodio $\mathrm{NaOH}$ al $1 \% \mathrm{M}$.

\section{Resultados}

Tabla 1

Resultados del lodo químico a diferentes concentraciones de coagulante y floculante

\begin{tabular}{ccccc}
\hline \multicolumn{5}{c}{ Peso(g) } \\
\hline M & Floculante & $\begin{array}{c}\text { Lodo del } \\
\text { Floculante }\end{array}$ & $\begin{array}{c}\text { Coagulante }(10 \mathrm{~g})+ \\
\text { Floculante }\end{array}$ & $\begin{array}{c}\text { Peso total } \\
\text { lodo químico }\end{array}$ \\
\hline Muestra 1 & 5 & 169 & 15 & 54 \\
Muestra 2 & 7.5 & 228.68 & 17.5 & 111.18 \\
Muestra 3 & 10 & 303 & 20 & 183 \\
Muestra 4 & 12.5 & 304.16 & 22.5 & 181.66 \\
Muestra 5 & 15 & 324 & 25 & 199 \\
\hline
\end{tabular}

Para cada una de las cinco muestras se añadió distintas concentraciones de floculante, las cuales produjeron diferentes volúmenes de lodo químico, obteniendo resultados variados.

Se observó que el menor volumen generado es de 169 gr y el mayor con 324 gr, determinando que la concentración óptima en pruebas de efectividad era la muestra 3 con una concentración de 10 gr de floculante donde se obtuvo 303 gr de lodo químico. Dicha muestra mantuvo de manera estable los parámetros fisicoquímicos del efluente tratado y no generó saturación ni tampón buffer de $\mathrm{pH}$.

Se realizó el registro de parámetros de cada una de las muestras, antes y después de añadir el coagulante y floculante respectivamente, para realizar la comparación y demostración de las variantes. 
Tabla 2

Resultados Muestra 1

\begin{tabular}{|c|c|c|}
\hline \multicolumn{3}{|c|}{ Datos Muestra 1} \\
\hline \multirow[t]{3}{*}{ Fecha } & & arámetros 21/05/2019 \\
\hline & $\mathrm{pH}$ & 6.5 \\
\hline & $\mathrm{T}^{\circ}$ & $13.8^{\circ} \mathrm{C}$ \\
\hline \multirow[t]{6}{*}{ Parámetros } & OD & $23.20 \%$ \\
\hline & EC & $2.14 \mathrm{mS} / \mathrm{cm}$ \\
\hline & TDS & 937ppm \\
\hline & NO3 & $5 \mathrm{mg} / 1$ \\
\hline & Turbidez & $198 \mathrm{NTU}$ \\
\hline & DQO & $200 \mathrm{mg} / 1$ \\
\hline \multicolumn{2}{|l|}{ Fecha } & Coagulante 24/05/2019 \\
\hline \multirow{5}{*}{ Parámetros } & & de $\mathrm{Al}_{2}\left(\mathrm{SO}_{4}\right)_{3}$ \\
\hline & $\mathrm{pH}$ & 3.01 \\
\hline & $\mathrm{T}^{\circ}$ & $13.9^{\circ} \mathrm{C}$ \\
\hline & OD & $53.10 \%$ \\
\hline & $\mathrm{EC}$ & $2.01 \mathrm{mS} / \mathrm{cm}$ \\
\hline \multicolumn{2}{|l|}{ Fecha } & loculante 28/05/2019 \\
\hline Parámetros & $\begin{array}{l}\text { Floculante } \\
\text { Arifloc } 301\end{array}$ & $5 \mathrm{~g}$ \\
\hline \multicolumn{2}{|c|}{ Fecha } & e Lodo Químico 30/05/2019 \\
\hline \multirow{2}{*}{$\begin{array}{c}\text { Parámetros } \\
\text { Fecha }\end{array}$} & $\begin{array}{l}\text { Peso del } \\
\text { Lodo }\end{array}$ & $169 \mathrm{~g}$ \\
\hline & & $\mathrm{n}$ de pH 31/05/2019 \\
\hline \multirow[t]{2}{*}{ Parámetros } & $\mathrm{NaOH}$ a $1 \mathrm{M}$ & $20 \mathrm{ml}$ \\
\hline & $\mathrm{pH}$ & 7.6 \\
\hline
\end{tabular}

Muestra $\mathbf{n}^{\circ}$ 1. El coagulante utilizado fue sulfato de aluminio $\mathrm{Al}_{2}\left(\mathrm{SO}_{4}\right)_{3}$ a una concentración estándar de $10 \mathrm{~g}$ denotado como referencia teórica. El floculante utilizado fue Arifloc 301 a una concentración de 5g, generando la neutralización de carga de los coloides electronegativos, aglutinando a los sólidos en suspensión presentes en el agua residual. Se tuvo como resultado la generación de lodo químico con un peso de 169g, al medir los parámetros de TDS, EC y turbidez se evidenciaron que los resultados aún eran altos.

Para la estabilización del pH se utilizó $\mathrm{NaOH}$ al 1\% molar y se obtuvo una estabilización 7.6 de pH llegando a ser alcalino.

Muestra $\mathbf{n}^{\circ}$ 2. El coagulante utilizado fue sulfato de aluminio $\mathrm{Al}_{2}\left(\mathrm{SO}_{4}\right)_{3}$ a una concentración estándar de $10 \mathrm{~g}$ denotado como referencia teórica. El floculante utilizado fue Arifloc 301 a una concentración de 7.5g, generando la neutralización de carga de los coloides electronegativos, aglutinando a los sólidos en suspensión presentes en el agua residual. Se tuvo como resultado la generación de lodo químico con un peso de $228.68 \mathrm{~g}$, al medir los parámetros de TDS, EC y turbidez se evidenciaron que los resultados denotaban disminución de turbidez y TDS, pero aún se mantenían un tanto elevados.

Para la estabilización del pH se utilizó $\mathrm{NaOH}$ al 1\% molar y se obtuvo una estabilización de 7.5 de pH llegando a ser alcalino. 
Tabla 3

Resultados muestra 2

\begin{tabular}{|c|c|c|}
\hline \multicolumn{3}{|c|}{ Datos Muestra 2} \\
\hline \multicolumn{2}{|l|}{ Fecha } & etros $21 / 05 / 2019$ \\
\hline \multirow{8}{*}{ Parámetros } & $\mathrm{Ph}$ & 8.14 \\
\hline & $\mathrm{T}^{\circ}$ & $13.9^{\circ} \mathrm{C}$ \\
\hline & OD & $21.20 \%$ \\
\hline & EC & $2.14 \mathrm{mS} / \mathrm{cm}$ \\
\hline & TDS & $937 \mathrm{ppm}$ \\
\hline & NO3 & $5 \mathrm{mg} / 1$ \\
\hline & Turbidez & $182 \mathrm{NTU}$ \\
\hline & DQO & $200 \mathrm{mg} / \mathrm{l}$ \\
\hline Fecha & \multicolumn{2}{|c|}{ Adición de Coagulante 24/05/2019 } \\
\hline \multirow{5}{*}{ Parámetros } & \multicolumn{2}{|c|}{$10 \mathrm{~g}$ de $\mathrm{Al} 2(\mathrm{SO} 4) 3$} \\
\hline & $\mathrm{Ph}$ & 3.11 \\
\hline & $\mathrm{T}^{\circ}$ & $13.9^{\circ} \mathrm{C}$ \\
\hline & OD & $50.30 \%$ \\
\hline & EC & \\
\hline Fecha & \multicolumn{2}{|c|}{ Adición de Floculante 28/05/2019 } \\
\hline Parámetros & Floculante Arifloc 301 & $7.5 \mathrm{~g}$ \\
\hline Fecha & \multicolumn{2}{|c|}{ Formación de Lodo Químico 30/05/2019 } \\
\hline Parámetros & \multicolumn{2}{|c|}{ Peso del } \\
\hline Fecha & \multicolumn{2}{|c|}{ Estabilización de pH 31/05/2019 } \\
\hline \multirow[t]{2}{*}{ Parámetros } & $\mathrm{NaOH}$ a $1 \mathrm{M}$ & $20 \mathrm{ml}$ \\
\hline & $\mathrm{pH}$ & 7.5 \\
\hline
\end{tabular}

Muestra n 3. El coagulante utilizado fue sulfato de aluminio $\mathrm{Al}_{2}\left(\mathrm{SO}_{4}\right)_{3}$ a una concentración estándar de $10 \mathrm{~g}$ denotado como referencia teórica. El floculante utilizado fue Arifloc 301 a una concentración de 10g, generando la neutralización de carga de los coloides electronegativos, aglutinando a los sólidos en suspensión presentes en el agua residual. Se tuvo como resultado la generación de lodo químico con un peso de 303g, al medir los parámetros de TDS, EC y turbidez se evidenciaron que los resultados denotaban una importante disminución en las mediciones.

Se tuvo como resultado la generación de lodo químico con 303g, peso obtenido por gravimetría, que está dentro de los parámetros establecidos en la generación de lodos por un litro de agua residual. Los TDS siguieron bajando y se denota un parámetro muy aceptable para la normativa vigente.

Para la estabilización del pH se utilizó hidróxido de sodio $\mathrm{NaOH}$ al $1 \%$ molar y se obtuvo una estabilización de 7.8 de pH llegando a ser alcalino.

Muestra n ${ }^{\circ}$. El coagulante utilizado fue sulfato de aluminio $\mathrm{Al}_{2}\left(\mathrm{SO}_{4}\right)_{3}$ a una concentración estándar de $10 \mathrm{~g}$ denotado como referencia teórica. El floculante utilizado fue Arifloc 301 a una concentración de 12.5g, generando la neutralización de carga de los coloides electronegativos, aglutinando a los sólidos en suspensión presentes en el agua residual. Se tuvo como resultado la generación de lodo químico con un peso de 304.16g, al medir los parámetros de TDS, EC y turbidez se evidenciaron una importante disminución, sim embargo la estabilización de pH se hacía menos viable porque comenzaba a formar un tampón buffer que impedía la elevación del pH ácido.

Se tuvo como resultado la generación de lodo con un peso de $304.16 \mathrm{~g}$, estando dentro de los parámetros establecidos en la generación de lodos por un litro de agua residual. Los TDS no bajaron en mayor proporción y el efluente se tornó acuoso 
Tabla 4

Resultados muestra 3

\begin{tabular}{|c|c|c|}
\hline \multicolumn{3}{|c|}{ Datos Muestra 3} \\
\hline Fecha & \multicolumn{2}{|c|}{ Control de Parámetros 21/05/2019 } \\
\hline \multirow{8}{*}{ Parámetros } & $\mathrm{Ph}$ & 8.42 \\
\hline & $\mathrm{T}^{\circ}$ & $13.6^{\circ} \mathrm{C}$ \\
\hline & OD & $23.08 \%$ \\
\hline & EC & $2.41 \mathrm{mS} / \mathrm{cm}$ \\
\hline & TDS & 937ppm \\
\hline & NO3 & $5 \mathrm{mg} / 1$ \\
\hline & Turbidez & 187 NTU \\
\hline & DQO & $200 \mathrm{mg} / \mathrm{l}$ \\
\hline \multirow[t]{3}{*}{ Fecha } & \multicolumn{2}{|c|}{ Adición de Coagulante 24/05/2019 } \\
\hline & $10 \mathrm{~g}$ de $A$ & $4) 3$ \\
\hline & $\mathrm{Ph}$ & 3.5 \\
\hline \multirow[t]{3}{*}{ Parámetros } & $\mathrm{T}^{\circ}$ & $14.6^{\circ} \mathrm{C}$ \\
\hline & OD & $52.60 \%$ \\
\hline & $\mathrm{EC}$ & $2.01 \mathrm{mS} / \mathrm{cm}$ \\
\hline Fecha & \multicolumn{2}{|c|}{ Adición de Floculante 28/05/2019 } \\
\hline Parámetros & Floculante Arifloc 301 & $10 \mathrm{~g}$ \\
\hline Fecha & \multicolumn{2}{|c|}{ Formación de Lodo Químico 30/05/2019 } \\
\hline Parámetros & \begin{tabular}{|l|} 
Peso del \\
Lodo \\
\end{tabular} & $303 \mathrm{~g}$ \\
\hline Fecha & \multicolumn{2}{|c|}{ Estabilización de pH 31/05/2019 } \\
\hline \multirow[t]{2}{*}{ Parámetros } & $\mathrm{NaOH}$ a $1 \mathrm{M}$ & $20 \mathrm{ml}$ \\
\hline & $\mathrm{Ph}$ & 7.8 \\
\hline
\end{tabular}

Muestra $\mathbf{n}^{\circ}$ 5. El coagulante utilizado fue sulfato de aluminio $\mathrm{Al}_{2}\left(\mathrm{SO}_{4}\right)_{3}$ a una concentración estándar de $10 \mathrm{~g}$ denotado como referencia teórica. El floculante utilizado fue Arifloc 301 a una concentración de $15 \mathrm{~g}$, generando la neutralización de carga de los coloides electronegativos, aglutinando a los sólidos en suspensión presentes en el agua residual. Se tuvo como resultado la generación de lodo químico con un peso de $324.0 \mathrm{gr}$, al medir los parámetros de TDS, EC y turbidez se evidenciaron que los parámetros habían bajado. No es tan óptimo porque excede los parámetros establecidos en la generación de lodos por un litro de agua residual obteniendo lodo voluminoso. No se permite medir TDS, efluente muy acuoso.

Para la estabilización del pH se utilizó hidróxido de sodio $\mathrm{NaOH}$ al 1\% molar y no se logró una estabilización de pH llegando a concluir que se había formado un tampón buffer. 
Tabla 5

Resultados muestra 4

\begin{tabular}{|c|c|c|}
\hline & \multicolumn{2}{|c|}{ Datos Muestra 4} \\
\hline \multicolumn{2}{|l|}{ Fecha } & rámetros 21/05/2019 \\
\hline \multirow{8}{*}{ Parámetros } & $\mathrm{Ph}$ & 8.87 \\
\hline & $\mathrm{T}^{\circ}$ & $13.8^{\circ} \mathrm{C}$ \\
\hline & OD & $21.20 \%$ \\
\hline & $\mathrm{EC}$ & $2.43 \mathrm{mS} / \mathrm{cm}$ \\
\hline & TDS & 937ppm \\
\hline & NO3 & $5 \mathrm{mg} / 1$ \\
\hline & Turbidez & 179 NTU \\
\hline & DQO & $200 \mathrm{mg} / \mathrm{l}$ \\
\hline \multirow[t]{2}{*}{ Fecha } & \multicolumn{2}{|c|}{ Adición de Coagulante 24/05/2019 } \\
\hline & $10 \mathrm{~g} \mathrm{de}$ & $4) 3$ \\
\hline \multirow{4}{*}{ Parámetros } & $\mathrm{Ph}$ & 4 \\
\hline & $\mathrm{T}^{\circ}$ & $14.6^{\circ} \mathrm{C}$ \\
\hline & OD & $52.40 \%$ \\
\hline & EC & $1.99 \mathrm{mS} / \mathrm{cm}$ \\
\hline Fecha & \multicolumn{2}{|c|}{ Adición de Floculante 28/05/2019 } \\
\hline Parámetros & Floculante Arifloc 301 & $12.5 \mathrm{~g}$ \\
\hline Fecha & \multicolumn{2}{|c|}{ Formación de Lodo Químico 30/05/2019 } \\
\hline Parámetros & $\begin{array}{l}\text { Peso del } \\
\text { Lodo }\end{array}$ & $304.16 \mathrm{~g}$ \\
\hline Fecha & \multicolumn{2}{|c|}{ Estabilización de pH 31/05/2019 } \\
\hline \multirow[t]{2}{*}{ Parámetros } & $\mathrm{NaOH}$ a $1 \mathrm{M}$ & $20 \mathrm{ml}$ \\
\hline & $\mathrm{Ph}$ & 5.1 \\
\hline
\end{tabular}

En la figura 1 se observa que se realizó el análisis de la cantidad de coagulante y floculante utilizado en cada muestra a fin de verificar que muestra era la más eficiente para la clarificación del efluente tratado y generación de lodo químico sin generar tampón buffer que permita la estabilización del pH, evidenciando que, a partir de 22,5g de floculante ya no se podía estabilizar el pH porque se generó el tampón.

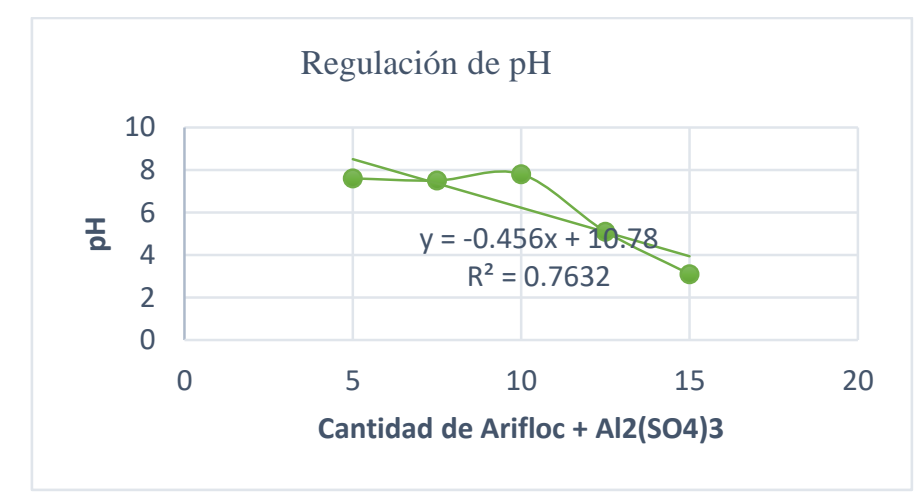

Figura 1. Estabilización del pH en relación a la cantidad de floculante 
Tabla 6

Resultados muestra 5

\begin{tabular}{|c|c|c|}
\hline & \multicolumn{2}{|c|}{ Datos Muestra 5} \\
\hline Fecha & \multicolumn{2}{|c|}{ Control de Parámetros 21/05/2019 } \\
\hline \multirow{8}{*}{$\begin{array}{l}\text { Parámetros } \\
\mathrm{M}<\mathrm{z}\end{array}$} & $\mathrm{Ph}$ & 8.87 \\
\hline & $\mathrm{T}^{\circ}$ & $14.1^{\circ} \mathrm{C}$ \\
\hline & OD & $22.20 \%$ \\
\hline & EC & $2.44 \mathrm{mS} / \mathrm{cm}$ \\
\hline & TDS & 930ppm \\
\hline & NO3 & $5 \mathrm{mg} / 1$ \\
\hline & Turbidez & $185 \mathrm{NTU}$ \\
\hline & DQO & $200 \mathrm{mg} / 1$ \\
\hline \multirow[t]{3}{*}{ Fecha } & \multicolumn{2}{|c|}{ Adición de Coagulante 24/05/2019 } \\
\hline & \multicolumn{2}{|c|}{$10 \mathrm{~g}$ de $\mathrm{Al} 2(\mathrm{SO} 4) 3$} \\
\hline & $\mathrm{Ph}$ & 3.01 \\
\hline \multirow[t]{3}{*}{ Parámetros } & $\mathrm{T}^{\circ}$ & $13.9^{\circ} \mathrm{C}$ \\
\hline & OD & $53.10 \%$ \\
\hline & EC & $1.94 \mathrm{mS} / \mathrm{cm}$ \\
\hline Fecha & \multicolumn{2}{|c|}{ Adición de Floculante 28/05/2019 } \\
\hline Parámetros & Floculante Arifloc 301 & $15 \mathrm{~g}$ \\
\hline Fecha & \multicolumn{2}{|c|}{ Formación de Lodo Químico 30/05/2019 } \\
\hline Parámetros & \multicolumn{2}{|c|}{$\begin{array}{ll}\text { Peso del } \\
\text { Lodo }\end{array}$} \\
\hline Fecha & \multicolumn{2}{|c|}{ Estabilización de pH 31/05/2019 } \\
\hline \multirow[t]{2}{*}{ Parámetros } & $\mathrm{NaOH}$ a $1 \mathrm{M}$ & $20 \mathrm{ml}$ \\
\hline & $\mathrm{Ph}$ & 3.1 \\
\hline
\end{tabular}

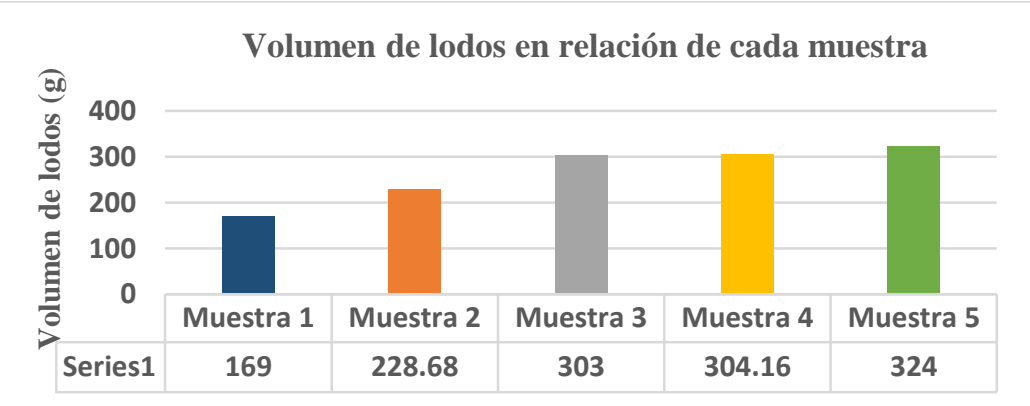

Figura 2. Volumen de lodos en relación de cada muestra

En la figura 2 observamos el volumen de lodo químico generado en cada una de las 5 muestras.

\section{Discusión}

Al realizar los procesos de tratamiento primario a través de operaciones unitarias de coagulación-floculación y estabilización de pH se evaluó la efectividad de los procesos de reducción de coloides y clarificación mejorando significativamente la concentración de TDS y disminuyendo eficientemente la turbidez de los efluentes. 
Es preponderante el conocimiento de las características físico químicas que tiene el efluente a tratar, para determinar el tipo de tratamiento de aguas residuales, evitando inconvenientes dentro de las operaciones. Se debe tener un control adecuado de las condiciones y los parámetros, en el contexto de que los resultados podrían varían significativamente.

Véliz (2010) señaló que la ozonización de aguas residuales se ha convertido en un método atractivo, debido al poder oxidante y bactericida del ozono, por lo que su combinación con otros procesos tales como la coagulación-floculación, significaría un aumento en la eliminación de la carga orgánica, inorgánica y microbiológica de las aguas residuales, además de aumentar las concentraciones de oxígeno disuelto en las aguas tratadas, lo que posibilitaría su reúso. Evaluó la eficiencia de cada proceso para la turbiedad, los sólidos suspendidos totales, el color, DQO, el pH y OD, así como la concentración de coliformes fecales. El esquema más eficiente resultó el de la coagulación-floculación con una posterior ozonización, con remociones de contaminantes físico químicos y de coliformes fecales superiores al $90 \%$ respectivamente. Del mismo modo en nuestra investigación determinamos lo importante de la aplicación de operaciones unitarias de coagulación floculación y estabilización de $\mathrm{pH}$ para la clarificación del efluente tratado y posterior tratamiento para la remoción de patógenos.

Determinar la dosis efectiva del coagulante- floculante es importante ya que si hay exceso o no llegamos a la cantidad optima influenciará directamente a la generación de lodos no tratados, pudiendo causar daños en la salud humana y provocar enfermedades, en ese sentido, el tratamiento primario es muy importante para la eliminación de coloides, partículas muy complejas de tratar. Se determinó la concentración eficiente de floculante con un volumen estándar de coagulante $\left(10 \mathrm{~g}\right.$ de $\left.\mathrm{Al}_{2}\left(\mathrm{SO}_{4}\right)_{3}\right)$ siendo éste de $10 \mathrm{~g}$ de Arifloc 301 para $1 \mathrm{~L}$ de efluente.

\section{Conclusiones}

Primera. Los tratamientos primarios para la reducción de coloides y clarificación de aguas residuales son eficientes en la medida que se consideren las concentraciones adecuadas y los parámetros físico químicos sean monitoreados de manera permanente.

Segunda. Es importante conocer las características del efluente a tratar, para ello se hace pertinente describir el origen de los mismos.

Tercera. Pudimos evidenciar que las sales de Aluminio reaccionan con la alcalinidad del agua y producen hidróxidos insolubles, favoreciendo a la formación del precipitado, estableciendo un puente químico donde las partículas de los coagulantes añadidos a la de los polímeros del floculante puedan absorber los coloides y microsólidos coadyuvando a la sedimentabilidad.

Cuarta. La concentración óptima es la que favorece a la aglutinación de los coloides y TDS sin afectar el proceso de regulación de pH para continuar con el tratamiento secundario que es la remoción de patógenos, en ese sentido determinamos que $10 \mathrm{~g}$ de floculante para $1 \mathrm{~L}$ de efluente tratado era la dosis óptima que no favorece al tampón químico o buffer que altere el proceso de tratamiento.

Quinta. Se concluyó que la relación 2:8 (lodo químico: efluente) se dio con la adición del floculante en volumen de 10g y coagulante 10g, respectivamente logrando un lodo químico de 303g. Reduciendo significativamente los TDS y la turbidez al finalizar la evaluación, mas no la remoción de patógenos. 
ANEXOS

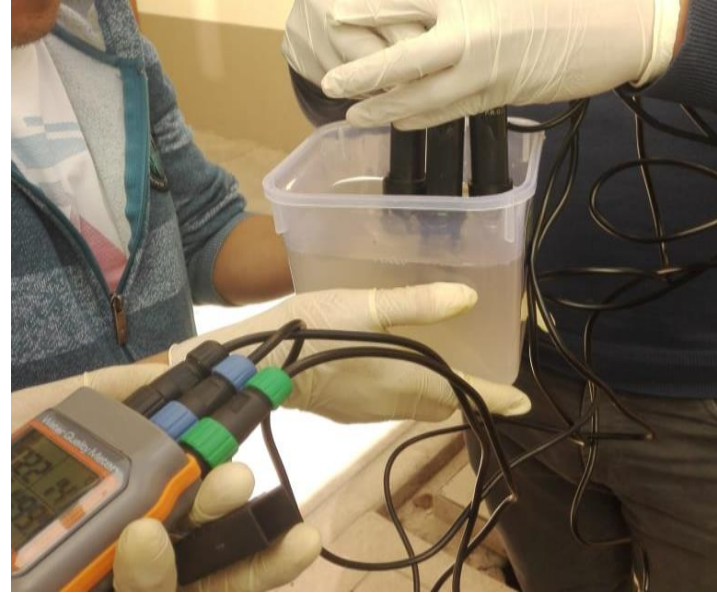

Figura 1. Uso del multiparámetro para determinar los parámetros físico químicos del efluente

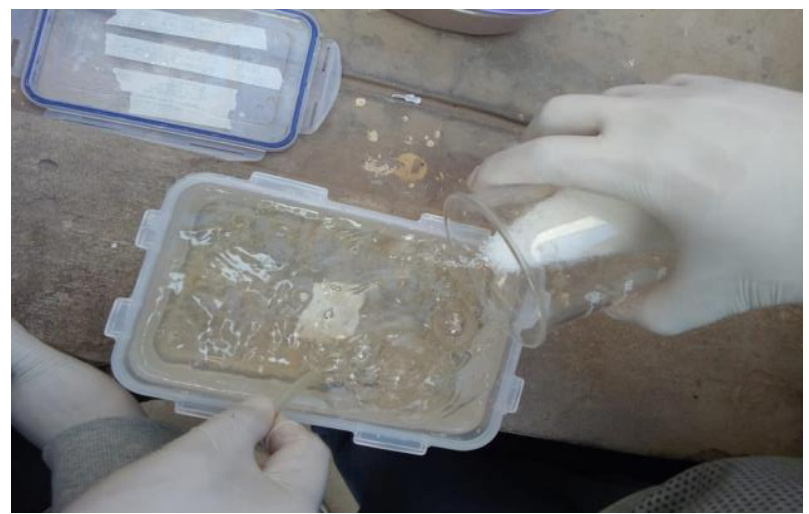

Figura 3. Adición del ARIFLOC

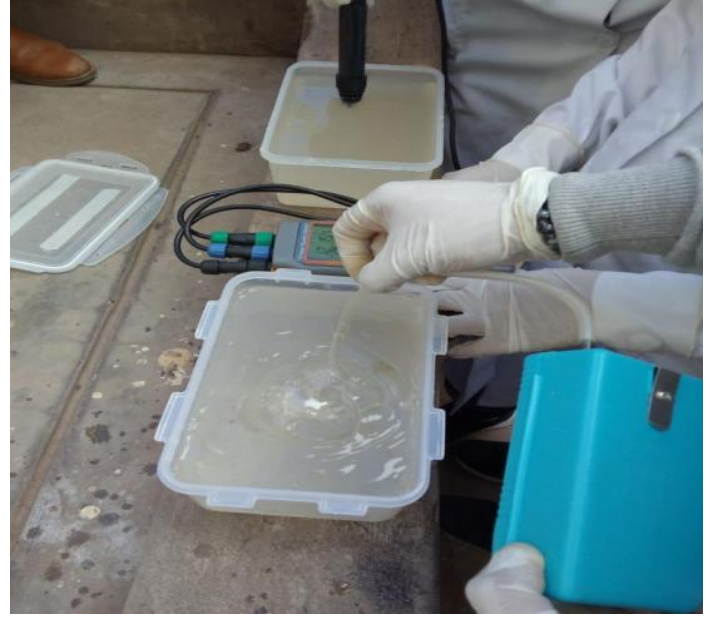

Figura 2. Adición del coagulante (con aereación)

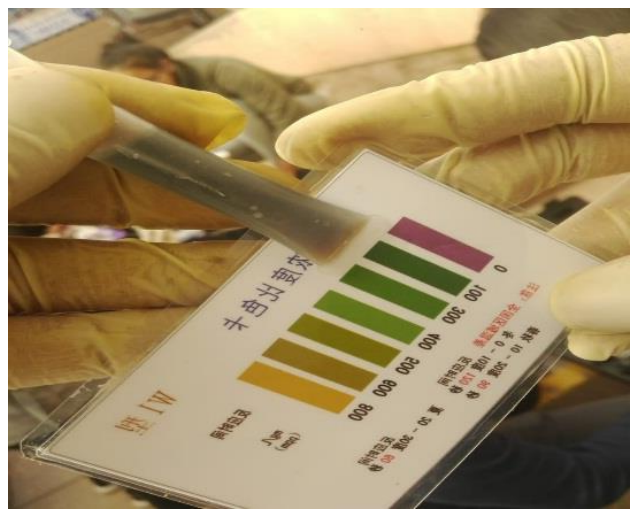

Figura 4. Medición de DQO

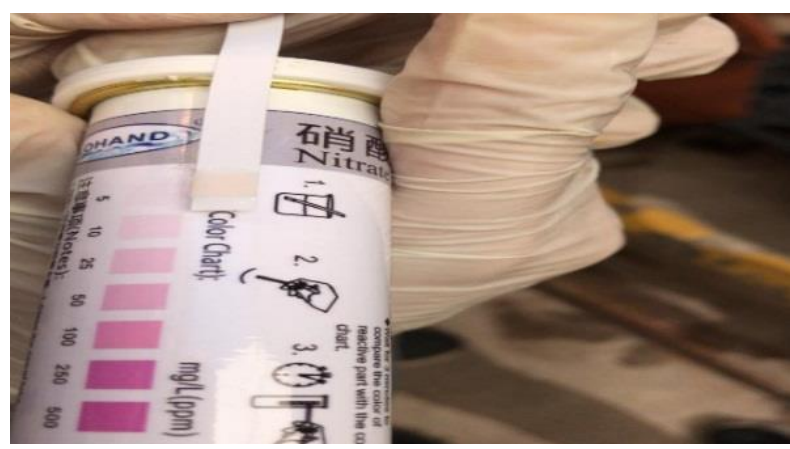

Figura 5. Medición de nitratos 


\section{Referencias bibliográficas}

Aguilar, M.I. (2002). Tratamiento físico-químico de aguas residuales: coagulaciónfloculación. Universidad de Murcia. I edición. España.

Andía C, Y. (2000). Tratamiento de agua coagulación y floración. 2019, de Evaluación de Platas y Desarrollo Tecnológico. Sitio

web:

http://www.sedapal.com.pe/c/document library/get_file?uuid=2792d3e3-59b74b9e-ae 55-

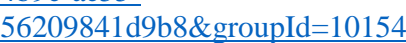

Barajas, C. (2015). Determinación de la dosis óptima de sulfato de aluminio (Al2(SO4)3 18H2O) en el proceso de coagulación - floculación para el tratamiento de agua potable por medio del uso de una red neuronal artificial. Universidad Santo Tomás sitio web: https://repository.usta.edu.co/bitstream/h
andle/11634/2916/Barajasclaudia2015.p df? sequence $=1 \&$ is Allowed $=y$

Foncodes Ayacucho. (1999). Seminario Taller: Sistemas de Tratamiento de Aguas Residuales y Disposición de Excretas para el Área Rural. Ayacucho.

Kiely, G. (1999). Ingeniería Ambiental. Fundamentos, Entornos, Tecnologías y Sistemas de Gestión. Ed. MacGraW Hill. Madrid.

Ramirez, Z.R (2000). Proceso de coagulaciónfloculación para el tratamiento de aguas residuales: desarrollo y utilización de nuevos compuestos para la reducción de lodos. Sistemamid-Coordinación de Ing. Ambiental. Universidad Autónoma de México

Restrepo, H.A. (2009). Evaluación del proceso de coagulación - floculación de una planta de tratamiento de agua potable. Tesis pregrado. Universidad Nacional de Colombia

Tejero, I. (2001). Asignatura: Ingeniería Sanitaria y Ambiental. Curso de Maestría en Ingeniería Sanitaria y Ambiental. Universidad de Cantabria. Santander España.

UNALM; UL; SNI. (2002). Copias de Curso: Desarrollo y Gerenciamiento de Proyectos de Tratamiento y Disposición Final de Aguas Residuales. Módulo I, II y III.

Veliz, L.E. (2010). Evaluación de la eficiencia de los procesos de coagulación-floculación y ozonización a escala de laboratorio en el tratamiento de aguas residuales municipales. Revista CENIC Ciencias Químicas, Vol. 41, No. 1, pp. 49-56, 2010
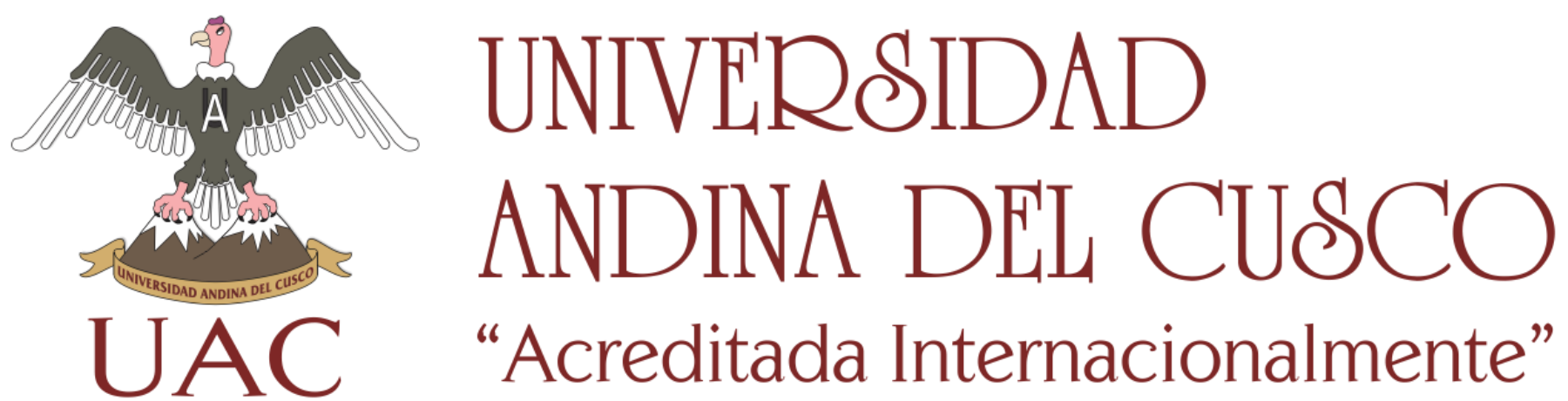

Rev. Yachay volumen (8) Número (1), enero-diciembre 2019 